\title{
Cloning and Sequence Analysis of Rabbit Interleukin-10 $(I L-10)$ Gene Promoter
}

\author{
${ }^{1,2}$ Mao Liu-Liu, ${ }^{3}$ Pan Yu-Lai, ${ }^{1,2}$ Wan Xiao-Ying, ${ }^{1,2}$ Wang Xiao-Ming, ${ }^{1,2}$ Feng Kai, \\ ${ }^{1,2}$ Zhang Lei, ${ }^{1,2} \mathrm{He}$ Meng-Jie and ${ }^{1,2} \mathrm{Wu}$ Xin-Sheng \\ ${ }^{1}$ Jiangsu Key Laboratory of Animal Genetics and Breeding and Molecular Design, \\ ${ }^{2}$ College of Animal Science and Technology, Yangzhou University, \\ Yangzhou, 225009 Jiangsu, China \\ ${ }^{3}$ Jinling Rabbits Farm, 211103 Nanjing, China
}

\begin{abstract}
To clone the IL-10 promoter of rabbit and analyse its sequence, this study amplified the 5 flanking region of rabbit IL-10, compared the genomes and used bioinformatics software to make a forecast. Then, the researchers comfirmed partial promoter sequences and analysed some transcription factors of the $I L-10$ gene promoter. The study showed that rabbit and human $I L-10$ gene promoter had some similarities which all cotained GAGA, CAAT and TATA. The transcriptional start site started from $-80 \mathrm{bp}$ of translation initiation codon (ATG) upstream region. The promoter also had some transcription factors such as AP-1, Myogenin, c-Ets-1, C/EBP alpha and so on. Results of this study predicted partial sequences, transcriptional start site and some transcriptional regulating factors binding sites of $I L-10$ gene promoter which would lay the foundation of lucubrating the expression and regulation of rabbit $I L-10$ gene.
\end{abstract}

Key words: IL-10, promoter, transcription factor, bioinformatics, gene, China

\section{INTRODUCTION}

IL-10 is a special cytokine which is secreted by cell Th2 and can restrain the mRNA transcription of Th1 cytokine. Therefore, it also can be called Cytokine Synthesis Inhibitory Factor (CSIF). Studies show that IL-10 has important immunoregulatory activities (Fickenscher et al., 2002) also it is closely related to the mechanism of many acute and chronic, autoimmune and parasitic diseases (Pestka et al., 2004; Alba Soto et al., 2010). For the past few years, scientists have made great progress at the research about disease susceptibility, severity and development process of human $I L-10$ gene promoter. However, the relationship between rabbit $I L-10$ gene promoter and parasitic diseases and some communicable diseases remains unknown. Thus, this experiment obtained partial sequences of rabbit $I L-10$ gene promoter did some correlated bioinformation analysis which would lay the foundation for further investigating the biological functions of rabbit $I L-10$ gene promoter sequences and its effect on diseases.

\section{MATERIALS AND METHODS}

DNA purification kits were bought from TaKaRa (Dalian) Co., Ltd. Proteinase K, DNA marker, LA-Taq enzyme, dNTP were supported by Sangon Biotech (Shanghai) Co., Ltd. Gene scloning verctor PTA2, DH5 $\alpha$ competent cell came from Dingguo Biotech (Beijing) Co., Ltd. Primer synthesis and sequencing were completed by sangon Biotech (Shanghai) Co., Ltd.

Prime designing: According to contrast the genome sequence of rabbit $I L-10$ gene (GenBank Accession No. DQ437508.2) and the rabbit genome, the researchers got $1000 \mathrm{bp}$ before start codon (ATG) and design the primers with primer 3.0. The sequence of primers are forward: 5'-cacggacacttgtgcagatt-3'; reverse: 5 '-ggaagaccaggcaacatagc- $3^{\prime}$. The product was 839 and 782 bp was located in 5'-upper stream of start codon (ATG).

Genomic DNA extraction and PCR condition: One New Zealand rabbit was randomly selected in Jinling Rabbits Farm (Nanjing, China). Approximately $5 \mathrm{~mL}$ blood was collected from the central artery vein of the rabbit ear into tubes containing $1 \mathrm{~mL} \mathrm{ACD} \mathrm{(citic} \mathrm{acid,} \mathrm{sodium} \mathrm{citrate,}$ dextrose) as anticoagulant and was then preserved in a$20^{\circ} \mathrm{C}$ freezer. Genomic DNA were extracted according to the Molecular Cloning-A Laboratory Manual (Joseph and David, 2001). About $20 \mu \mathrm{L}$ PCR mixture contained $2 \mu \mathrm{L}$ of $10 \times$ Buffer, $0.4 \mu \mathrm{L}$ of $10 \mathrm{mmol} \mathrm{L}^{-1} \mathrm{dNTP}, 0.2 \mu \mathrm{L}$ of $5 \mathrm{U}_{\mu} \mathrm{L}^{-1}$

Corresponding Author: Wu Xin-Sheng, College of Animal Science and Technology, Yangzhou University, 225009 Yangzhou, China 
Taq DNA polymerase, $1 \mu \mathrm{L}$ of $10 \mathrm{pmol} \mathrm{L} \mathrm{L}^{-1}$ forward and reverse primers each, $1 \mu \mathrm{L}$ of genomic DNA (about $100 \mathrm{ng} \mu \mathrm{L}^{-1}$ ) and $14.4 \mu \mathrm{L}$ of $\mathrm{ddH}_{2} \mathrm{O}$. Amplification of DNA was conducted for 40 cycles follwing the conditions as below; preliminary degeneration at $95^{\circ} \mathrm{C}$ for $5 \mathrm{~min}$, degeneration at $94^{\circ} \mathrm{C}$ for $30 \mathrm{sec}$, annealing at $59^{\circ} \mathrm{C}$ for $40 \mathrm{sec}$, extension at $72^{\circ} \mathrm{C}$ for $60 \mathrm{sec}$ followed by a final extension at $72^{\circ} \mathrm{C}$ for $10 \mathrm{~min}, 2 \mu \mathrm{L}$ of $6 \times$ bromophemol blue beffer were added into $5 \mu \mathrm{L}$ of PCR products which were loaded into the $1.0 \%$ sepharose gel. Electrophoresis was carried out at a voltage of $150 \mathrm{~V} \mathrm{~cm}^{-1}$ for $20 \mathrm{~min}$ and the electrophoresis results were observed by the ultraviolet lamp and photographed.

Purification, connection, transformation and sequencing of product: Cloning of DNA product was conduct by the steps as below; purificated the PCR product by agarose gel DNA purification kit, connected the product with PTA2 vector ( $5 \mu \mathrm{L}$ of $2 \times$ Ligation buffer, $3 \mu \mathrm{L}$ of DNA product, $1 \mu \mathrm{L}$ of PTA2 vector, $1 \mu \mathrm{L}$ of T4 DNA ligase), stored the mixture in $4^{\circ} \mathrm{C}$ for about $12 \mathrm{~h}$, transfected the mixture into $E$. coli $\mathrm{DH} 5 \alpha$, inoculated the infectious $E$. coli on the LB agarose plate and then cultivated in $37^{\circ} \mathrm{C}$ for $12-14 \mathrm{~h}$, picked single strain and inoculated in the $\mathrm{LB}$ liquid medium to raise in $37^{\circ} \mathrm{C}$ for $12-14 \mathrm{~h}, 220 \mathrm{r} \mathrm{min}^{-1}$. After taking $1 \mu \mathrm{L}$ inocula to carry on the PCR apprisal, send the positive sample to sequence.

Sequence analysis and structure prediction of promoter: Forcasted the obtained sequence $\mathrm{CpG}$ island of 5'-upstream of rabbit $I L-10$ gene with the CpGIsland Searcher soft ware of http://www.uscnorris. com/cpgisland2/cpg.aspx (Takai and Jones, 2002). Predicted the promoter and transcriptional start site with http://www.fruitfly.org/seq-tools/promoter.html. Estimated the transcription factor binding sites with TESS of http://www.cbil.upenn.edu/cgi-bin/tess and TFsitescan of http://www.ifti.org and then chose the sites which got high score in these two software. At last, the researchers had a comparison with human and the obtained rabbit promtor seqence to select the highly conservative binding sites.

\section{RESULTS AND DISCUSSION}

The PCR products were detected with $1.0 \%$ agarose gel. The product obtained was the same as the target fragmet and and the product stra was chear without mixed strap. Thus, the product was amplified with fine stability and specificity (Fig. 1). According to the prediction of

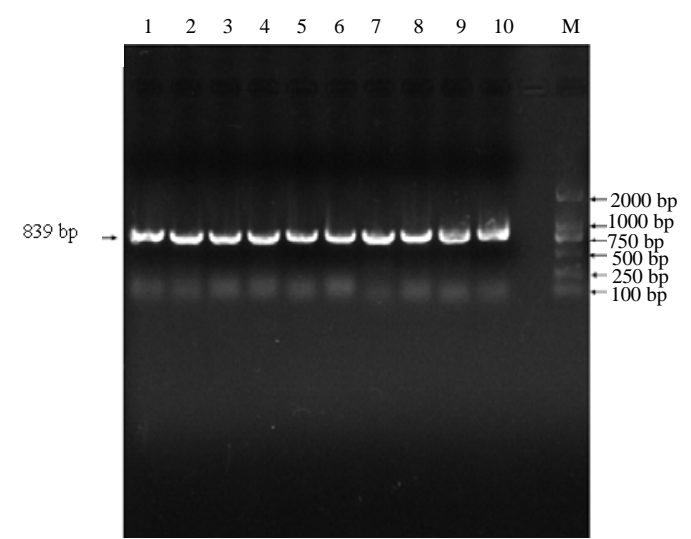

Fig. 1: PCR product of 5 ' upstream of rabbit $I L-10$ gene; M: 2000 bp DNA ladder Marker; lanes 1-10: Individual PCR product

$\mathrm{CpG}$ island searcher there were no $\mathrm{CpG}$ island in the obtained $5^{\prime}$ upstream of rabbit $I L-10$ gene and the content of $\mathrm{G}$ and $\mathrm{C}$ was $55 \%$.

Structure analysis of $I L-10$ gene promoter: Before the translation initiation codon (ATG) of $I L-10$ gene, the product was $782 \mathrm{bp}$. The researchers could get patial rabbit $I L-10$ gene promoter sequence through the prediction of software and with the comparison of the $782 \mathrm{bp}$ and human $I L-10$ gene promoter (Fig. 2). TATA box (TATAAA) and GAGA box (GAGAGA) were both found in rabbit and human $I L-10$ gene promoter however, CAAT box was only in the former. The transcription start site was the basy $1 \mathrm{G}$ which located in $-80 \mathrm{bp}$ of translation initiation codon (ATG) upstream region.

According to the TESS and TFsitescan software, the researchers could get some transformation factors from the obtained sequence which were ordered by the points and the arrangement of 5'-3' are Myogenin, c-Ets-1, MEF2B, PRB, Oct-R, C/EBP alpha, EBP 40, POU1Fla and AP-1. Among these factors, PRB, EPB40, POU1F1a were only found in rabbit and Myogenin, c-Ets-1, MEF-2B, Oct-R, $\mathrm{C} / \mathrm{EBP}$ alpha, AP-1 were highly conservative and in the same location of human and rabbit $I L-10$ gene promtor. It could presume that the factors make certain effect to the expression and regulation of rabbit $I L-10$ gene.

Importance of $I L-10$ gene promoter: IL-10 can inhibit the synthesis and activity of pro-inflammatory mediator, besides, it has synergistic effects with anti-inflammatory mediator. Therefore, it has fairly strong anti-inflammatory effects. For decades, studies about $I L-10$ gene promoter have made great progress but we still know little about its 


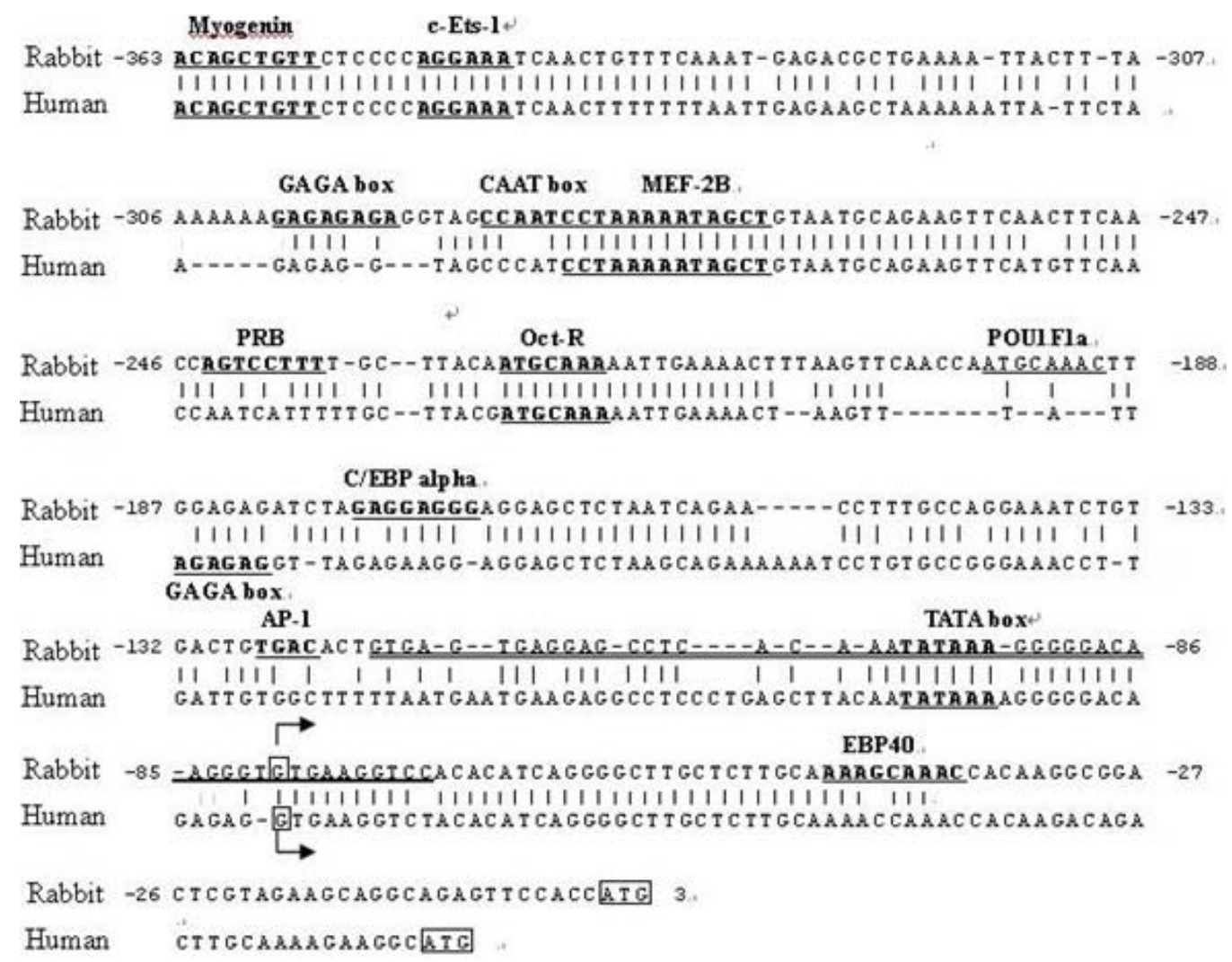

Fig. 2: Contrast of the rabbit and human $I L-10$ gene promoter and some binding sites of transformation factors

transcriptional regulating factors. If the transcriptional regulation of $I L-10$ gene was clearly known, the researchers could know more about the expression of IL-10 in both healthy and unhealthy individuals and then the researchers could treat some diseases through the regulation of its expression.

Structure prediction of rabbit $I L-10$ gene promoter: This study cloned partial sequences of the 5 ' flanking region of rabbit $I L-10$ gene and compared them with the region of human IL-10 promoter which was published in GenBank. Results showed that partial sequences had high similarities. Besides, the promoter sequences predicted by software and the location of TATA box could identify the sequences as a part of rabbit $I L-10$ gene promoter. Human IL-10 promoter sequence published in GenBank was 4018 bp, locating in upstream -29 -4047 bp of start codon.

When compared with rabbit $5^{\prime}$ flanking region, the same region was in $-29 \sim-348$ bp. So, the researchers supposed that the same gene promoter sequence in different species had some conservatism while partial sequences also had large variabilities.
Some important basic elements of rabbit $I L-10$ gene promoter: Rabbit IL-10 promoter subsequences contained TATA box, GAGA box, CAAT box and so on which constructed mammals' promoter. TATA-box was the first identified promoter element of eukaryotes. Generally, it located in the $24 \sim 36$ bp region ahead of transcriptional start site and its existence made great contributions to the efficiency of genetic transcription. Studies showed that once TATA-box had mutation, the efficiency of genetic transcription would decrease, worsely, the transcription might even be prevented. While the distance between CAAT box and transcriptional start site made little difference to its function and both the positive and negative directions had their roles. CAAT box had a great effect on determining the efficiency of promoter transcription which could strengthen the intensity of promoter. Until now, the researchers still knew little about the effect of GAGA element on gene expressional regulation of mammals.

Some reports said that GAGA element took part in the transcriptional regulation of some genes in vertebrates such as angiotonin $I$ acceptor gene II, African toad stromelysin-3 gene, serine protease inhibitor-2.1 gene 
and so on (Wyse et al., 2000; Li et al., 1998). While the component and structure of protein compounds which was conjugated to GAGA element were still unknown (Volpi et al., 2002).

About $>2000$ transcription factors of mammals have been identified and many instrument software that can analyse the binding sites of transcription factors have been discovered which all lay the foundation of investigating the effect of transcription factors on gene expressional regulation by bioinformatics (Bulyk, 2003).

Analysing rabbit IL-10 promoter subsequence which was amplified through the above conditions, the researchers found some related transcriptional factors including Myogenin, c-Ets-1, MEF-2B, PRB, Oct-R, C/EBP alpha, AP-1 and so on. Some reports indicated that transcriptional factor AP-1 had transcriptional activation, moreover, AP-1 binding site existed in gene promoters of multitude inflammatory cell factors and growth factors which prompted that AP-1 might take part in the transcriptional regulation of cell factors and growth factors expression and then influenced the function of body immune system, participated in regulating the expression of inflammatory reaction genes. C/EBP alpha is one of the main members in family $\mathrm{C} / \mathrm{EBP}$ which have multiple functions. C/EBP together with other Rho factors, compose complicated but subtile regulational network. They play an important role on cell multiplication and differentiation, tumorigenesis, organism immunity and stress reaction (Dan et al., 2009; Hai-Zheng et al., 2009; Xia et al., 2009).

Besides, the existence decisively affects the expression of some genes. Until now, the comprehension of most transcription factors' molecular mass or function is still at the foundational stage, the effect of other related factors on IL-10 has to be investigated through further studies.

\section{CONCLUSION}

This study presumed rabbit $I L-10$ gene promoter and partial transcription factors through related Bioinformatic software and did some correlated analysis which would provide a theoretical basis for the effects of this gene in disease process and the regulation of transcriptional level.

\section{ACKNOWLEDGEMENTS}

This study was supported by the earmarked fund for Modern Agro-industry Technology Research System (Grant No. CARS-44-1) and Jiangsu High Technology Project (Grant No. BG2007325).

\section{REFERENCES}

Alba Soto, C.D., M.E. Solana, C.V. Poncini, A.M. Pino-Martinez, V. Tekiel and S.M. Gonzalez-Cappa, 2010. Cells devoid of IL-10 induce protective immunity against the protozoan parasite Trypanosoma cruzi. Vaccine, 8: 7407-7413.

Bulyk, M.L., 2003. Computational prediction of transcription factor binding site locations. Genome Biol., 5: 201-201.

Dan, Z.X., F. Wen-li and H. Zong-gan, 2009. Effect of enhancer-binding protein C/EBPá on differentiation and apoptosis of K562 cells and its possible mechanism. Tumor, 29: 220-225.

Fickenscher, H., S. Hor, H. Kupers, A. Knappe, S. Wittmann and H. Sticht, 2002. The interleukin-10 family of cytokines. Trends Immunol., 23: 89-96.

Hai-Zheng, W., W. Ying, S. Da-Quan and L. Ding-Gan, 2009. Molecular mechanism of tumor suppression activity of C/EBPâ mRNA 3'UTR: Simultaneous deletion of 3 short sequences in the $3^{\prime} \mathrm{UTR}$ reduces its tumor suppression activity. Prog. Biochem. Biophys., 36: 1134-1140

Joseph, S. and W.R David, 2001. Molecular Cloning: A Laboratory Manual. 3rd Edn., CSHL Press, Cold Spring Harbor, pp: 483-485.

Li, J., V.C.T. Liang, T. Sedgwick, J. wong and Y.B. Shi, 1998. Unique organization and involvement of GAGA factors in transcriptional regulation of the Xenopus stromelysin-3 gene. Nucleic Acids Res., 26: 3018-3025.

Pestka, S., C.D. Krause, D. Sarkar, M.R. Walter, Y. Shi and P.B. Fisher, 2004. Interleukin-10 and related cytokines and receptors. Annu. Rev. Immunol., 22: 929-979.

Takai, D. and P.A. Jones, 2002. Comprehensive analysis of GpG islands in human chromosomes 21 and 22. Proc. National Acad, Sci., 99: 3740-3745.

Volpi, S., C. Rabadan-Diehl, N. Cawley and G. Aguilra, 2002. Transcriptional regulation of the pituitary vasopress in V1b receptor involves a GAGA-binding protein. J. Biol. Chem., 277: 27829-27838.

Wyse, B.D., S.L. Linas and T.J. Thekkumkara, 2000. Function role of a novel cis-acting element (GAGA box) in human type-1 angiotensin II receptor gene transcription. J. Mol. Endocrinol., 25: 97-108.

Xia, W., H. Hu, Z. Wei-nan, P. Ze-min, J. Xu-peng, Z. Dong-Hui and P. Ze-min, 2009. The research progress of nuclear transcription factor $\mathrm{C} / \mathrm{EBP} \beta$. Prog. Mod. Biomed., 9: 3198-3200. 